\title{
AN ANALYSIS BETWEEN SPATIAL RELATIONSHIPS AND SHORT SEA SHIPPING IMPACTS ON MESSINA'S WATERFRONT
}

\author{
A. PRATELLI ${ }^{1}$, A. ROSSELLI ${ }^{2}$, A. FARINA ${ }^{1} \&$ M. LUPI ${ }^{1}$ \\ ${ }^{1}$ University of Pisa, Department of Civil and Industrial Engineering, Italy \\ ${ }^{2}$ Tuscany Region, Bureau of Logistics Facilities and Management, Italy
}

\begin{abstract}
This study aims to investigate how the port waterfront structure of the city of Messina can be resilient against the stresses induced by road freight transport, and generated by the port, because of Short Sea Shipping activities. For this study, the configurational approach of the Space Syntax Analysis was used, in order to consider the relationship between the spaces of the urban grid. This urban grid has considered, on one hand as the primary matrix of the settlement processes, and on the other hand as an ordering factor for the formation of social relations between the individuals. The case study is significant due to the presence of a strong historical matrix linking the spaces of the port infrastructure with the urban structure, and such a condition appears to be common to most medium-sized Mediterranean port cities. The present work is divided into three analytical phases: (a) Structuring: geometric definition of the urban grid considering various historical periods; (b) Characterization: configurational analysis of the urban grid in the various historical periods; (c) Interaction: analysis of the relational effects of heavy freight traffic generated by the port on the configuration of the urban grid as defined above.

Keywords: port waterfront, Short Sea Shipping, space syntax analysis, urban grid.
\end{abstract}

\section{INTRODUCTION}

In this paper, Space Syntax Analysis techniques have been used in planning the Messina urban - port waterfront, in order to identify possible vulnerabilities in relation to the type of traffic generated by the Short Sea Shipping (SSS) activities of the port. It is a two-level approach, which looks on one side to the urban structure as a whole, and on the other side to the peculiarity of the waterfront subsystem, trying to understand the structural relationships between the part and the whole. This work is guided by the assumption that Space Syntax analyses can help us obtain valuable information on the relational qualities of urban spaces and their usability. The analysis of the configurational properties of the city of Messina is the first step towards understanding these relationships and represents a useful tool for qualifying the vulnerability of the urban structure to the heavy traffic flows generated by the port. With the Space Syntax Analysis, the structure of the city is defined exclusively by its own urban grid, represented through axial lines corresponding to publicly accessible open spaces - the so-called "axial maps" - without considering the spatial dimensions of the street spaces or the actual functions that insist on them.

A portion of the city of Messina has been examined, which extends: from the railway arch on southward to Viale Giostra on northward for a length of about $4.5 \mathrm{~km}$, and from the urban coast on eastward up to the panoramic road on westward for a width of about $1.8 \mathrm{~km}$. The borders of the study area are real and distinct barriers, both for the intersection with higherlevel roads and for the presence of physical constraints (railway, coastline to the east, escalators of the Peloritani Mountains to the west). Such study area is well defined and it consists of a significant section of the city of Messina.

In Section 2, the methodology is briefly described. In Section 3, the studied urban area, belonging to Messina, has been framed. In Section 4, the configurational properties of the 
urban grid are analysed, as well as the interaction of the urban space with the Short Sea Shipping, (SSS) traffic. Conclusions and future research developments have been discussed in Section 5.

\section{METHODOLOGY}

\subsection{Model and data set}

The cartography used as a basis for digitization has extracted from the open data platform OpenStreetMap ${ }^{\circledR}$ (OSM), whose data are distributed by the OpenStreetMap Foundation (OSMF) under the Open Data Commons Open Database License (ODbL). The digital cartography contained in the OpenStreetMap ${ }^{\circledR}$ tables has been released under Creative Commons ${ }^{\circledR}$ license. The extraction of the cartographical basis was carried out directly in the QGIS ${ }^{\circledR}$ workspace, an open source GIS software (GNU general public license), by downloading separately road graphs and punctual components (urban services and residences).

Following the method of the Space Syntax [1], all convex spaces, characterizing the publicly accessible urban mesh, have been taken into consideration for the tracking of the axial maps. Both the tracks internal to the parks and to the pedestrian areas, and the parking lanes, have been neglected.

As regard to diachronic maps, reference was made to historical maps found freely on the web, by choosing those related to 1714 (prior to the earthquake of 1783) and 1868 (prior to the earthquake of 1908). As regards the data related to the volumes of Ro-Ro goods and traffic, generated by SSS, at the port of Messina, reference has made to the statistics published by Assoporti/SRM, Rete Autostrade Mediterranee and the Messina Port Authority. The topological elaborations on the axial maps were carried out with the open source multi-platform software DepthmapX for the analysis of spatial networks, following the methodology proposed by Al Sayed [1].

\subsection{Configurational indicators}

For each type of analysis (both Axial Analysis and Segment Angular Analysis) the relative configurational indexes, reported in the following Table 1, have been elaborated:

Table 1: Configurational indexes.

\begin{tabular}{lll}
\hline Indicators & Axial analysis & Segment angular analysis \\
\hline Integration & Integration HH & Integration \\
& Integration HH R3 & Integration R400m \\
Choice & Choice & Choice \\
& Choice R3 & Choice R400m \\
Correlation & Integration HH/HH R3 & Integration/Integration R400 \\
\hline
\end{tabular}




\subsection{Methodology description}

The theoretical basis of the Space Syntax Analysis, developed starting from the 1980s by Bill Hillier and Julienne Hanson of UCL (University College of London) [2], [3], [4], was the main reference for the development of the elaborations described in the following paragraphs.

Initially, we proceeded to discretize the urban space of the field of study considered by reducing it to a one-dimensional system of linear segments that connect single convex spaces. These consist of portions of urban space characterized by a substantial perceptive unity [5]. The set of such linear segments, which constitutes the so-called axial map (or urban grid), assumes the meaning of the plot of the visual connections between the individual perceptive units of the settlement [6], [7]. The relationships established between the elements of the urban grid, thanks to their mutual connection, take on meaning.

Subsequently, the axial map has been transformed into a tree graph, in which each link corresponds to an axial line of the grid and each node represents an intersection between lines. In this way, a network of $k$ nodes is built, for which it is possible to calculate several structure indexes, which allow to clarify the topological relationships that exist between the nodes (i.e. between the axial lines of the grid). At first, for each element of the grid, the structure value of the average depth is calculated. This last gives a quantitative measure of the belonging to the grid of each single element, through which the other configurational parameters (or indexes) are defined [8].

The average depth $D_{M i}$ of $i$ th line, with respect to all the other lines of the grid, is a function of the total depth $D_{T i}$ and it should be written through the following expressions:

$$
D_{M_{i}}=\frac{D_{T_{i}}}{k-1} \quad \text { with } i \neq j
$$

where:

$$
D_{T_{i}}=\sum_{j=1}^{k-1} D_{i j} \quad \text { with } i \neq j
$$

The connectivity index $C_{\mathrm{i}}$ of the $i$ th line is calculated: by constructing the adjacency matrix [A] of dimension $(k \times k)$, and by summing for each row; in this way a vector of $k$ values $C_{\mathrm{i}}$ is obtained, which corresponds to the number of direct connections of each node $i$, i.e. to the number of intersections of the $i$ th line:

$$
C_{i}=\sum_{j=1}^{k} n_{i j} \quad \text { with } i \neq j
$$

where $n_{i j}=$ number of direct connections between nodes $i$ and $j$, whose value is 1 .

Then, the most significant index, among all configurational parameters, was calculated: the integration index $I_{\mathrm{i}}$, representing the average depth of the $i$ th axial line with respect to all the other lines of the grid. It corresponds to the closeness parameter, which defines the average distance of a node within a graph as follows:

$$
I_{i}=\left(\sum_{j=1}^{k} d_{i j}\right)^{-1} \text { with } i \neq j
$$


where $d_{i j}$ is the topological distance between nodes $i$ and $j$ of the graph, measured according to the shortest path among this pair of nodes.

Another configurational parameter, used in this work, is the global choice index, $C h_{\mathrm{i}}$, which is defined as the frequency with which an axial line falls within the paths of lower topological length connecting the other axial lines of the grid [6], [7]. In order to calculate this index, we use the betweeness parameter of the graph theory, which has been expressed as follows:

$$
C h_{i}=\sum_{j} \sum_{k} \frac{f_{j k}(i)}{f_{j k}}
$$

where $f_{j k}(i)$ is the number of paths of minimum topological distance between nodes $j$ and $k$, and crossing the node $i$, while $f_{j k}$ is the total number of shortest paths between nodes $j$ and $k$.

In order to estimate the synergy, or correlation, index $R^{2}$, it was calculated the regression line between: the series of values $X_{\mathrm{i}}$ of the local integration index having a topological radius equal to 3 (Integration $\mathrm{HH} r=3$ ), and the series of values of the global integration index $Y_{\mathrm{i}}$ (Integration $\mathrm{HH} r=n$ ).

Finally, values of the variance of $X$ and $Y$, and of the covariance of $X Y$ have calculated; it was also calculated the $R^{2}$, whose value points out the proportion of the variability of $Y$ explained by the variable $X$ through the regression model [9]:

$$
R_{X Y}^{2}=\frac{C O V_{X Y}^{2}}{V A R_{X} V A R_{Y}}=\frac{\sigma_{X Y}^{2}}{\sigma_{X}^{2} \sigma_{Y}^{2}}
$$

\section{URBAN EVOLUTION}

\subsection{Evolution of Messina urban structure}

The definition of Sicily given by Leonardo Sciascia, one of the most famous Italian novelists, is: " 1,039 kilometers of coasts -440 on the Tyrrhenian Sea, 312 on the sea of Africa, 287 on the Ionian Sea. But this great island of the Mediterranean, in its way of being, in its life, seems all turned inward, clinging to the highlands and to the mountains, intent on escaping from the sea and on excluding it behind a curtain of hills or walls, to give itself the most complete illusion that the sea does not exist" [10]. In this masterful image of the insular condition of Sicily it is possible to capture the highest notes of the urban history of Messina, the regulatory substrate of a structure whose articulations constitute, over the centuries, punctual responses to local contingent needs or to programs imposed by the reason of State.

The city of Messina rises on the Eastern coast of Sicily, near the strait that takes its name, in an alluvial plain between the coastline and the first slopes of the Peloritani mountains. The earliest settlements in the Messina area belong to the Hellenistic and Roman period, with a first phase of expansion during the Middle Age. A second phase of northward and southward expansion was carried out starting from the first half of the XVI Century, according to an orthogonal urban layout and a perimeter of the defense walls that remained until the XIX Century. From 1622, after the demolition of the walls along the port margin, the first "Palazzata" was built, "monumental scenery of buildings drilled by doors which connected the port with the city" [11], aimed at representing the city with renewed magnificence, since Messina 
had become one of the main Mediterranean ports of the "Silk Road". The building curtain, about $25 \mathrm{~m}$ high ( 88 palms), was periodically interrupted to allow the transverse connection between the city and the port. This construction was completely destroyed by the earthquake of 1783, nevertheless it was rebuilt in 1809 with the new "Palazzata" of Marvuglia [11]. The "Palazzata", the most civic pride and icon of the city, was a curtain of majestic neoclassical palaces, adorned with a monumental Ionic colonnade, about $20 \mathrm{~m}$ high (77 palms), and in front of the port arc for about $1 \mathrm{~km}$; these palaces were punctuated by 37 doors that connected the coast with the rest of the city. Such a majestic building, image of the new mercantile local aristocracy, was destroyed in its whole by the earthquake of 1908, together with almost the whole city, erasing the ancient testimonies of the past [11].

Thus, the new city of Messina was born, according to the Masterplan, drawn up by Luigi Borzì and approved in 1911, which conceived a city almost completely new, characterized by a poor population density, low-rise multifamily housing (no more than three levels), long straight roads $14 \mathrm{~m}$ wide, orthogonal plan, and checkerboard urban blocks, which is coupled with anti-seismic technology. This Masterplan remained essentially valid until the 1960s [12].

The Borzì Masterplan (see Fig. 1) kept the urban layout of the pre-earthquake city, but it also included the enlargement of the city, with the doubling of the urban area towards north and south and along the city streams. The walls, which closed Messina towards the Peloritani, were replaced by a highway ring, that nowadays borders the City.

The Borzì Masterplan did not provide for the reconstruction of the "Palazzata", due to the fact that the Government Commission forbade the construction of "new buildings destined to permanent residences near the beach", and imposed "a distance of at least $100 \mathrm{~m}$ from the external edge of the docks or from the shoreline of the sea".

The reconstruction of the "Palazzata" was shelved until 1930, when a competition was announced for the project of a new "Palazzata", halved in height and width compared to the previous one and with volumes separated by roads, instead of the prior building curtain. The

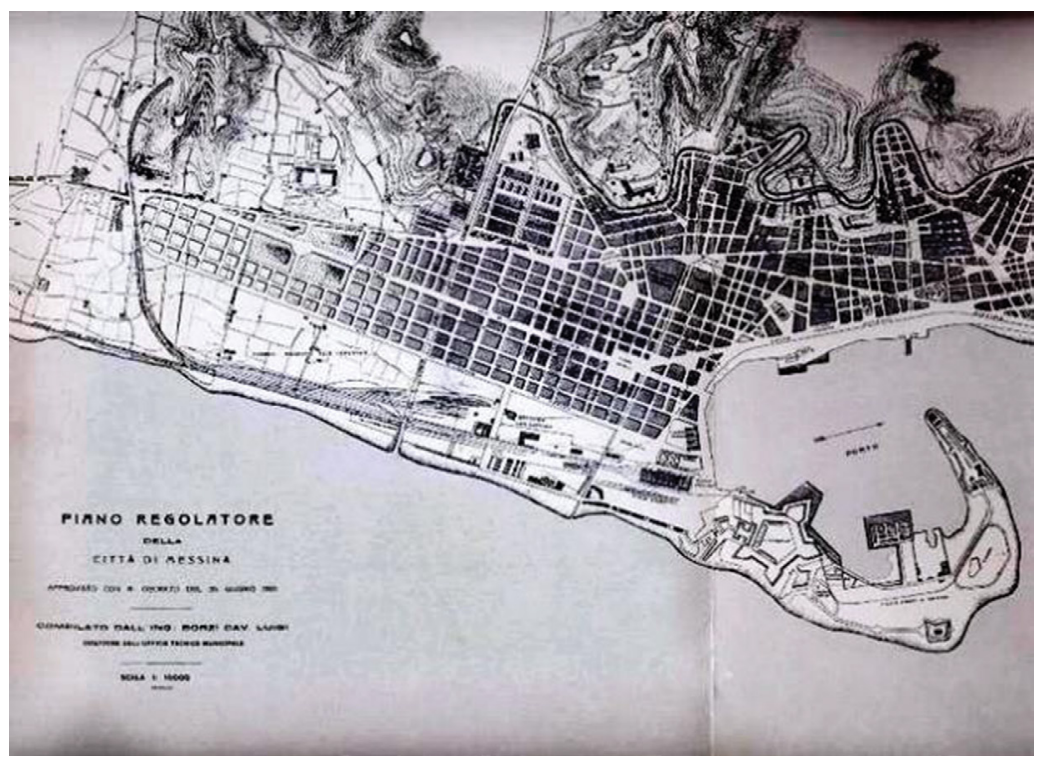

Figure 1: General layout from the 1911 Borzì Masterplan of Messina. Source: [14]. 


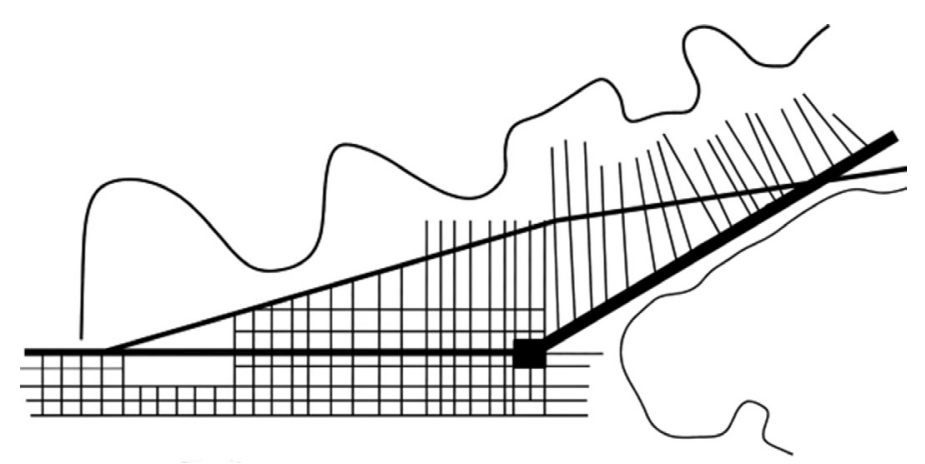

Figure 2: Road grid ideogram, reconstructed from the Borzì masterplan, 1911.

winning project included eleven buildings aligned on the front of the port between Corso Vittorio Emanuele and Corso Garibaldi. Of the planned blocks, only those closest to the customs and to the Banco di Sicilia, on the southward, were built as planned [13]. The axis of the new city on the southward of the port was constituted by Viale S. Martino, while along the footprint of the ancient walls, on the land side, a panoramic winding ring road was created.

In the Borzì Masterplan, the urban expansions both to northward and southward were connected through the two main arterials, or road axis, of Viale San Martino and of Via Garibaldi. On Viale San Martino the new Quartieri Mosella and Quartiere Lombardo were inserted, in a checkerboard urban pattern. Instead Via Garibaldi constitutes the avenue along the seaside of the City; on this road the cross roads to the mountains are radially inserted. Both the two main arterials cross in Piazza Cairoli, which is located at the edge of the area where the ancient Hellenistic city once stood.

On 1863 started the construction of the Messina-Syracuse railway line, also called the "Dorsale Ionica", which departs from the southern part of the port, and goes along the coastline on the southward of Messina. This railway line has been a barrier to the urban development of the new districts Mosella and Lombardo towards the sea. Therefore, the 20th Century city was entrapped between the railway and the northern ring road, which had replaced the ancient 16th Century walls.

The present Messina is therefore, still today, bordered by the sea only along the ancient port arch, similar to a sickle shape, that ends with the Braccio di San Ranieri and the ruins of the Fortezza del Salvatore.

\section{CONFIGURATIONAL PROPERTIES OF THE URBAN GRID}

\subsection{City of Messina: configurational properties on 1714}

We are going to apply the Space Syntax Analysis to the Messina urban grid, in order to characterize the evolution over time of its effective relational structure, and to better understand the role of the waterfront with respect to the city's urban grid. Therefore, we will examine the urban grids of time periods that are chronologically distant from each other, but which, for the purpose of this research, will be particularly representative of the diachronic development of the city. 
These are the urban structures of Messina in the years 1714 (prior to the earthquake of 1783), 1868 (prior to the earthquake of 1908), and the current one, which derives substantially from the 1911 Masterplan of Luigi Borzì. The maps of 1714 and 1868 were also chosen because the urban settlement of the time was contained entirely in the Renaissance city walls. The axial map corresponding to the 1714 layer is composed of 332 axial lines in total. The local integration map of radius 3 , and relative to the year 1714 , shows a structure of more integrated lines, defined by selecting the most integrated lines corresponding to the 90 th percentile. These lines are arranged in a "herringbone" configuration, with a longitudinal integration axis in a North-South direction represented by the current Corso Cavour, on which some routes, that connect transversally the port to the urban center, are grafted orthogonally. The nucleus of local integration is shifted towards the inner part of the urban pattern, excluding the port waterfront from the most accessible urban network. Despite being internal, the nucleus of local integration expands towards the sea thanks to two lines that have high local integration values, corresponding to the current via Battisti and via Garibaldi, which connect the center of Messina with the urban pattern behind the 17th-Century "Palazzata" that characterized the port arch.

When comparing these lines with the global integration model, and selecting the most integrated lines corresponding to the 90th percentile, we have a confirmation of the existence of an integration nucleus. Such integration nucleus was lengthened in the NE-SW direction; one end of it corresponded to one of the south gates of the city and was located in the area corresponding to the current Rione Tirone, whose major axis coincides with the arterial of Corso Cavour. The substantial overlap between the integration core at the local level and that at the global level makes it possible to understand how the hierarchy of the road system of 1714 appears substantially based on the axis of the current Via Cavour, which represents the ordering element of the whole mesh.

Compared to this nucleus, the lines that define the waterfront are less integrated, as they seem to constitute a preferable destination essentially at the local level. The 18th-century Messina waterfront does not appear to be attractive of the natural movement regulated by the topology of the urban grid, and it evidently plays a specialized role in relation to the port activities that took place there. Indeed, the Messina's waterfront attracted flows, but only those connected to the commercial and logistic activities present there.

From the analysis of the spatial distribution of the indicators of local and global integration, as described above, it arises spontaneously to ask both whether, and to what extent, there is a correlation between the distribution of global integrators and that of local integrators. Roughly speaking, whether there is any relationship between the various parts of the city and the city as a whole. For this purpose the synergy index $R^{2}$ was calculated, which, in the case under analysis, is 0.5904 (Fig. 3): this is a fairly significant value of the existence of a good general correlation between the two relational scales.

But, if we consider the distribution of the integration values of the axial lines that identify the waterfront, we obtain very low and rather scattered values, with a synergy index of 0.04 (Fig. 4): these values cannot be compared with those related to the lines of the integration core, for which we find a synergy index of 0.89 (Fig. 5). This leads to the conclusion that the waterfront in Messina of 1714 played a very specialized role and was not particularly relevant in terms of the most used urban routes. The city was therefore mainly oriented towards the interior, despite presenting on the front of the port a unitary image characterized by the 17th-century "Palazzata". 


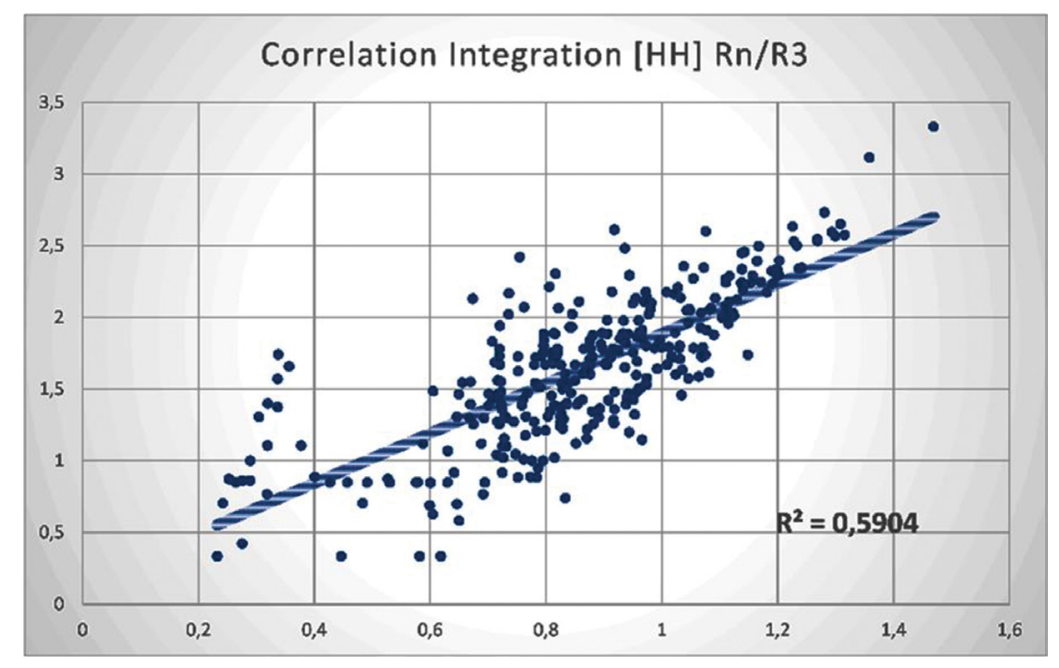

Figure 3: Global/local correlation, 1714.

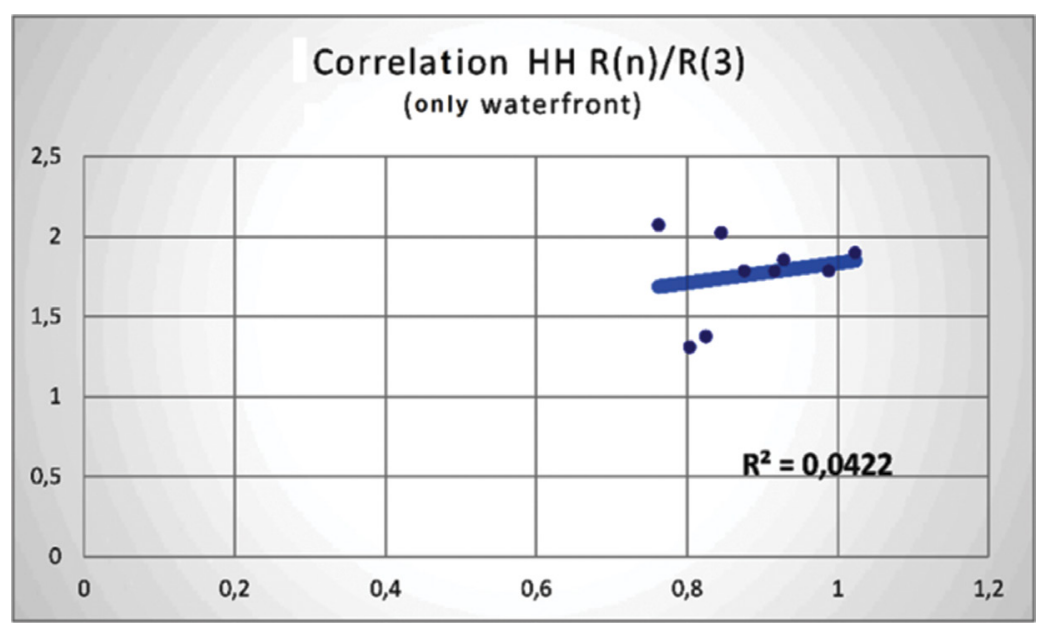

Figure 4: Global/local correlation, waterfront, 1714.

\subsection{City of Messina: configurational properties in 1868}

One hundred and forty years later the situation changed: after the disastrous earthquake of 1783 , the city was rebuilt on the grounds of the previous one and over of time it expanded towards north and south, saturating all the free spaces within the Renaissance walls. The axial map corresponding to the 1868 layer is therefore composed of a total of 937 axial lines, almost three times those of the 1714 grid.

The locally and globally more integrated axial lines are still oriented from north to south, but this time it is not only the current Via Cavour that possesses the greatest integration; the current Via XXIV Maggio on the west and Via Garibaldi on the east also collaborate with it, 


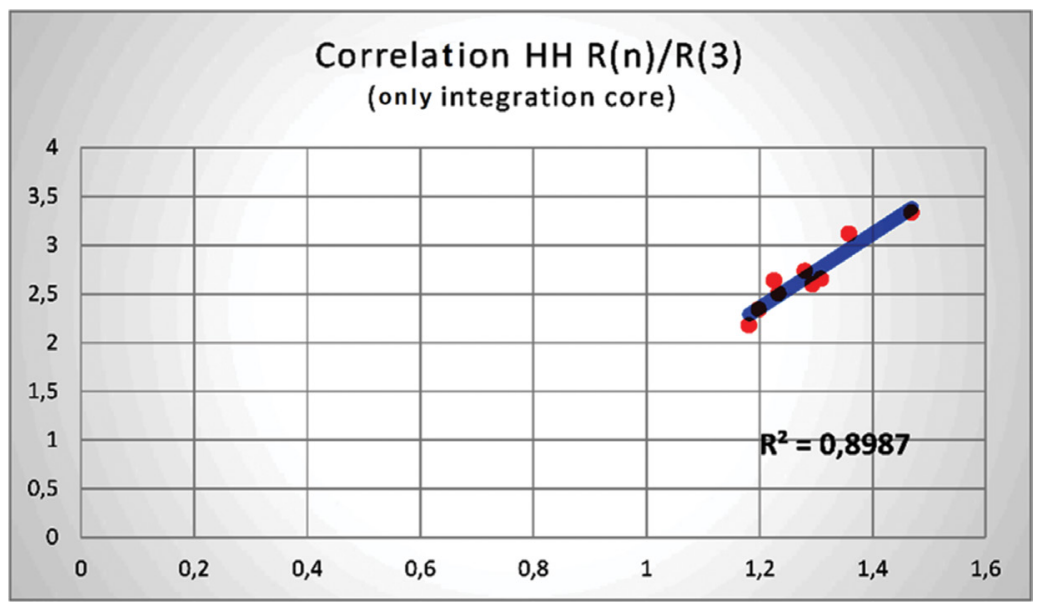

Figure 5: Global/local correlation, integration core, 1714.

defining three integration nuclei of which the central one is the one with the highest values and is located near the central arc of the port waterfront. The Via Garibaldi takes on a high role of control over the transversal flows between the front of the port and the inner quarters of the city center, since its axial line is intersected by lines with high value of both local and global integration.

High values of local integration can also be found on the transversal of the current Via Boccetta which at the time was the main access road to the city on the landside. The local integration of the transversal structure has not changed substantially, but the importance of the axial lines, that are connected to the structure of the port waterfront area, has increased, as well as the values of global integration of Via Garibaldi and Via Battisti have grown considerably. In the map of 1714, the Messina global integration nucleus was located in the city center. In 1868 , it became more complex and moved eastwards to include the port arc.

The effect that this entails on the port waterfront is actually amazing. In fact, the high values of the global integration index of the East-West transversal are not limited to the margin of the Via Garibaldi, but they continue until they connect, with high global integration values, also the actual port margin, corresponding to the current Via Vittorio Emanuele II, the place where the new "Palazzata" rises. It has rebuilt after the earthquake of 1783, and it not only provided a new solemn representation of the city of Messina to the mercantile and noble classes that visited the city coming from the sea, but also allowed to connect the spaces of the port waterfront to the inner part of the city. This way, it consolidated, also through the spatial configuration of the urban pattern, the image of Messina as a true Mediterranean port city.

To confirm the actual existence of natural flows coherent with the topology of the new integration core, the values of the global choice index have calculated. The distribution of the values of this index actually confirms the existence of a structure of displacement flows distributed over three North-South axes (Via XXIV Maggio, Via Cavour and Via Garibaldi), which extends to include the southern arc of the port waterfront. Therefore, the central role of the 19th-century port waterfront, in the relational dynamics generated by the urban grid, has confirmed, both in terms of potential flows (represented by the integration index) and in terms of actual movement flows, which the choice index in the Syntax Analysis is able to represent. The measure of the synergy index in this case is 0.6266 , which represents a very high value, 


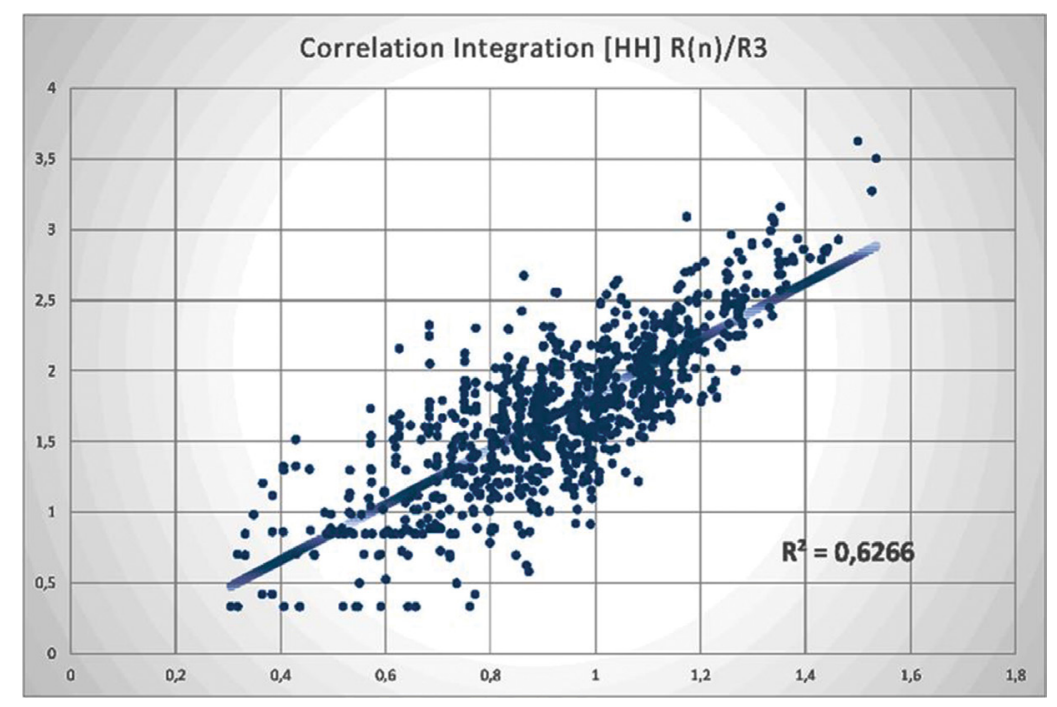

Figure 6: Local/global correlation, 1868.

confirming what was previously asserted concerning the unambiguous definition of the core of integration of the urban grid on 1868, and the central role of the port waterfront (Fig. 6).

\subsection{The contemporary Messina: definition of the urban grid}

As reported before in the introduction, it was examined a portion of the city of Messina, corresponding to the 20th century city, which has been completely redesigned with the Borzi plan of 1911 and its subsequent developments.

The borders of such study area constitute real and distinct barriers to the development of urban patterns. They have identified in the upper and lower intersections with the connection roads, which consist of the transversal guidelines of Viale Gazzi in the south and of Viale Giostra in the north; these two roads connect the urban area with the A18 motorway. The other borders have been identified due to the presence of barriers and physical limits, respectively represented by the railway line Messina-Syracuse on the eastside and the steepness of the Peloritani mountains on the westside. Therefore, it seems that the study area appears well defined as it describes a significant part of the city of Messina. The graph of the urban grid was extracted from the OpenStreetMap platform, indicated in the introduction, and has been reworked in the Cad environment in order to reduce the number of axial lines to the strictly necessary, according to the principle of the Axial Analysis "the longest and the fewest" [1]. Figure 7 shows the urban grid that has subjected to spatial analysis.

\subsection{Current configurational properties}

\subsubsection{Local integration $R=3$ and $R=7$}

The axial map corresponding to the 2019 layer is composed of an amount of 1794 axial lines, about twice those of the 1868 grid. After the disastrous earthquake of 1908, Messina was rebuilt and according to the structure defined by the Borzì master plan of 1911 mentioned above, 


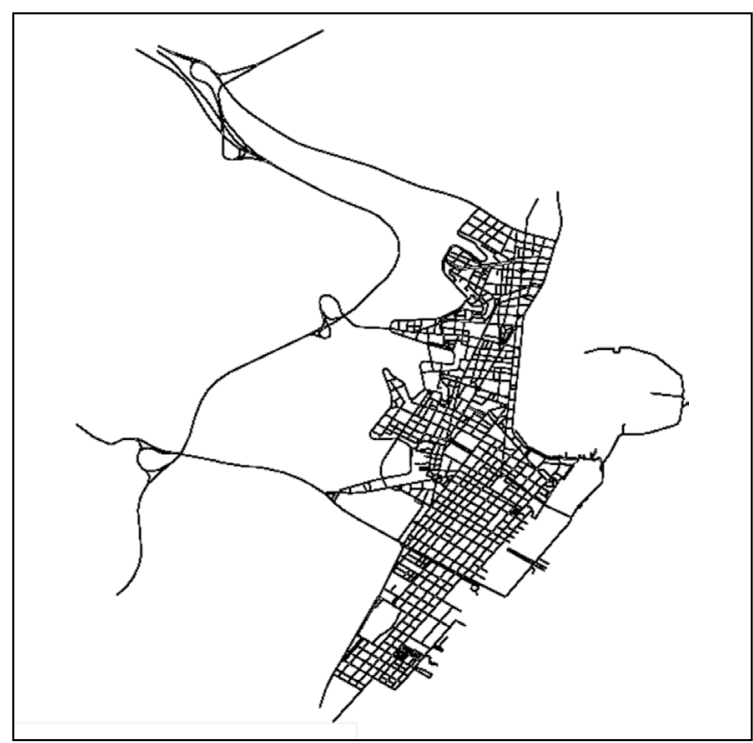

Figure 7: Current urban grid of Messina (year 2019).

which substantially it has been used until the 1960s. The 20th-century Messina is very different from that of the previous reconstruction, as regards both the urban structure and the dimension. In fact it is built following a very regular order, with orthogonal meshes and wide and rectilinear roads, going beyond the limits of the ancient Renaissance walls and increasing, from the first plant, both towards the south, with the Mosella and Lombardo districts, and towards the north, beyond the old border of the current Via Boccetta. The configurational analysis of the new urban grid, therefore, allows to highlight the different system of topological relations that this subtends, and the changed role played by the waterfront in the new urban configuration.

The distribution of the local integration index with radius $=3$ varies between a minimum value of 0.2109 to a maximum of 3.9863, but in the field of values above the 80th percentile (range between 3.2312 and 3.9886) there are only 8 lines of the 1,794 axial lines. Starting from the basis of this information it is possible to identify a local integration nucleus inserted onto the axis of via Garibaldi and extended towards the south.

The configuration of the local integration core for $R=3$, appears to be confirmed also in the light of the indicator distribution for $R=7$ and $R=15$, which appears substantially superimposable to the first one, but with greater detail in identifying, in the urban grid, the axial lines most representative of the potential to attract on them both pedestrian and vehicular traffic flows.

The highest integration values make it possible to identify a second-order articulation of the integration nucleus that appears to indicate the existence of three sub-areas:

1. The aforementioned western portion of the Moselle district between Via dei Mille and Via Battisti;

2. The nucleus, almost orthogonal to the first one, and oriented in an east-west direction, between Via La Farina and Via XXIV Maggio;

3. The axis of Via Garibaldi and its northern transversals, which connect the northern port arc to the inner city. 
Essentially, the 20th-century city appears to be centered on the most western urban grid of the Moselle district, which during the twentieth century progressively assumed the role of a central location; in fact, in this area there is the greatest density of commercial activities compared to other areas of the city. A different logic distribution has assumed by the services of public interest that tend to be located along the main longitudinal roads, such as Via Garibaldi, Via XXIV Maggio and Corso Cavour.

There is a poor density of commercial activities on the waterfront, although there are services of public interest. The fact of not being a privileged destination for natural urban movements, makes the port arc a specialized area whose operation does not depend on topological relations with the inner part of the City. Moreover, this issue occurs regardless of the actual physical segregation, which, for such a space, has been implemented through the security line that completely closes the port area with respect to the city.

\subsubsection{Global integration $R=n$}

The situation is clearly confirmed by the distribution of the values of the global integration index for $R=n$ (Fig. 8), which, in the range above the 80th percentile, contains only three axial lines, represented by Via Garibaldi, Via dei Mille and the transversal of Via Cannizzaro. The first two longitudinal axial lines, distributed along the north-south direction, actually identify the main ridge onto which the 20th-century urban grid is inserted, according to the original Borzì master plan, and confirming their strategic role in the system of relations between one part and the other of the city.

The global integration values assumed by the axial lines that compose the contemporary Messina waterfront are from $14 \%$ to $30 \%$ lower than the highest value assumed by the Via Garibaldi axial line; this difference in the integration index leads us to think that the role of the waterfront in the preferable destinations of the city is rather marginal. Messina seems again turned towards its interior, with its back to the sea. The most attractive paths are positioned to the west of Via Garibaldi, which, despite being a strong integrator, is still located behind the first urbanized strip of the waterfront and runs parallel to the port arc, without ever intercepting it.
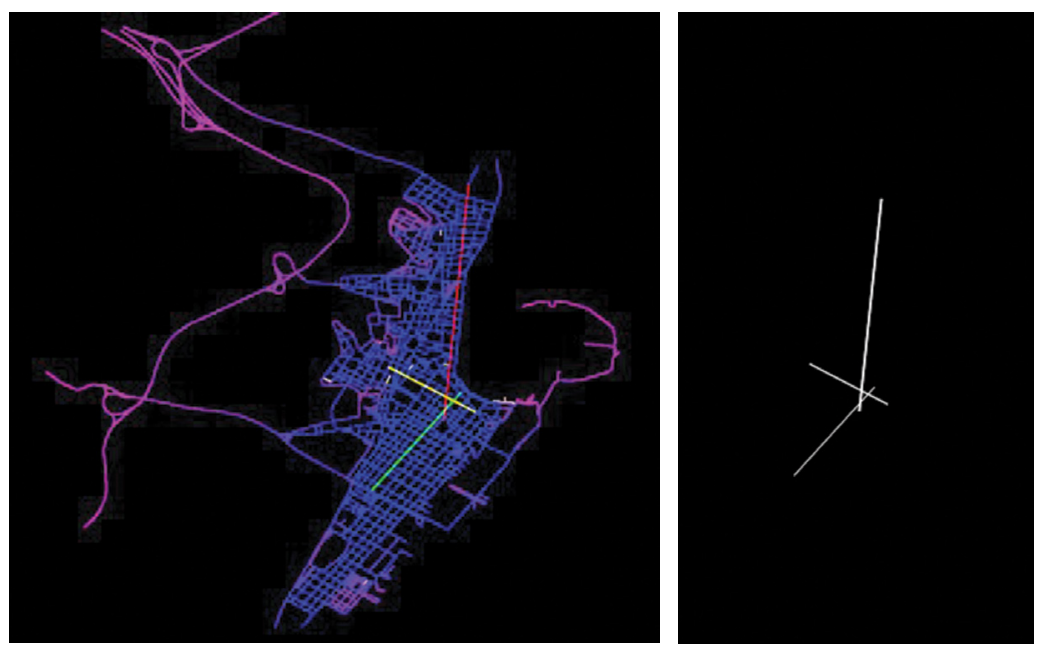

Figure 8: Global integration $R=n, 2019$. 


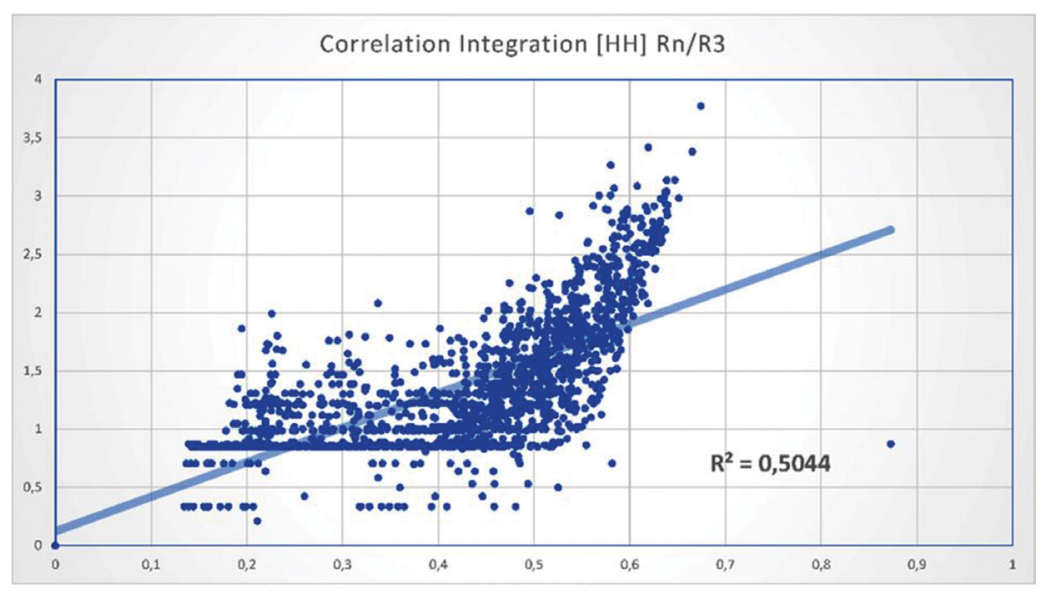

Figure 9: Local/global correlation, 2019.

Also in this last case, using the $R^{2}$ synergy index, we verify the quality of the correlation existing between the topological depths $R=3$ and $R=n$, so as to better understand the value of the relationships between the part and the whole (Fig. 9). The value $R^{2}=0.5044$ is lower than that calculated for the 19th-century urban grid $\left(R^{2}=0.6266\right)$, however it is indicative of the existence of a good correlation between the configuration assumed by the urban grid at the local scale compared to that assumed at the scale of the entire city.

The decrease in the synergy index of the 20th-century grid, with respect to the 19th-century one, also leads us to deduce that, in the new configuration of urban spaces deriving from the Borzì plan, the increase in complexity of the integration core has produced a greater weight of local relations than of system relations. This last result means that it is a greater accessibility of the local road network than that of longer distance.

In any case, if it is analyzed in more detail, the local distribution of global integration values for the two subsystems of the waterfront and of the integration core leads to obtain a result apparently in contrast. It is due to the fact that the synergy index for the waterfront axial lines is 0.78 while the synergy index related to the integration core is 0.71 (see Fig. 10). Therefore, it is also noted that the role of the waterfront, when placed into the system of preferable routes, is much less marginal than it might seem. In fact, the values of the synergy index, assumed by the axial lines that compose it, tell us that there is a strong correlation between the local topological scale and the global one, even greater than that assumed by the integration nucleus. The conclusion can be drawn deducing that the waterfront represents a second nucleus of integration complementary to the first and connected to this through the most integrated transversal lines, and whose role in attracting flows of natural movement is independent from that of the main integration nucleus. This seems to lead to defining the existence of a diversified (but not alternative) area with respect to the inner city, which is also able to constitute an element of attraction for urban flows.

\subsubsection{Global choice $R=n$}

The thesis introduced in the previous paragraph is confirmed, if one considers the effective distribution of urban services with respect to the distribution of the values of the global choice index (Fig. 11); the points in pink, which represent urban services, appear to focus on the axes that assume the highest values of the index. 

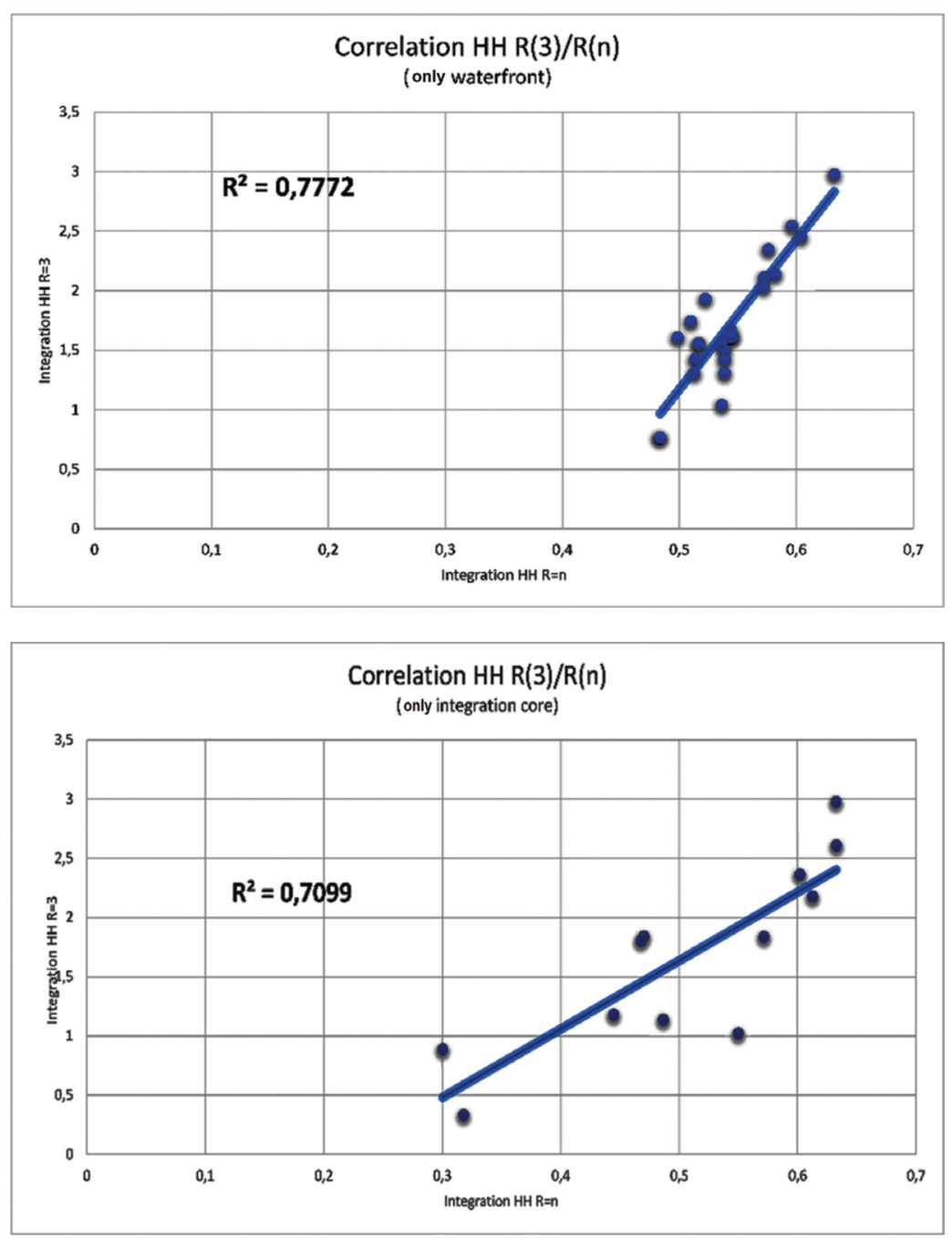

Figure 10: Local/global correlation (by sectors), 2019.

The global choice index, also known as "betweeness", identifies the paths that benefit from the greatest preference for taking on traffic flows from one area of the city to another. They are therefore preferred axes for displacements, of entry or exit to/from an urban zone, or of crossing.

The map of Fig. 11 highlights:

1. the urban ring road system;

2. the roads connecting the port with the A18 motorway;

3. the waterfront road system and its north and south connection to the roads of entrance/ exit in the city;

4. the localization relationship between urban services, retailers and global choice index.

In particular, the road network of access/exit, which feeds the port arch of the Falcata and the waterfront of Via Vittorio Emanuele II, seems to be basically based on Viale Europa, and 


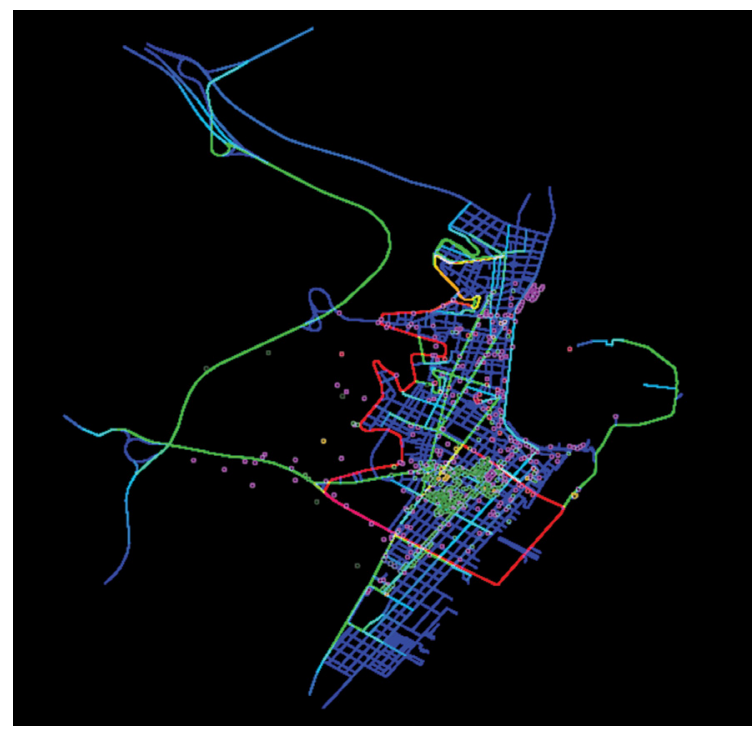

Figure 11: Facilities, commercial and global choice $R=n, 2019$.

connects the port through Via Ugo Bassi and the branch of Via Giuseppe Sciva overlapping the railroad. Actually, the connecting road is not Via Bassi but Via La Farina, which has been the most adequate road section to bear the port traffic in both directions, and this appears consistent with the values of the local integration index for $R=3$, which are high for Via La Farina. The algorithm of the Syntax Analysis is independent from the physical dimension of the road segments, since it has as object only the connection between them. This is an abstraction that is functional in identifying the existence of potential connections not yet updated, but which, theoretically, could become updated.

It directly follows that the port arc constitutes a particular type of centrality, more linked to the flows of long-distance movement (access/exit, crossing) than to the local intra-urban movement; as such it is directly connected to the extra-urban viability and constitutes a modal termination of it. In effect, the port of Messina constitutes a terminal for the Motorways of the Sea and SSS maritime transport.

Nevertheless, since the Syntax Analysis disregards the actual uses of urban spaces, this leads us to deduce that, also in this case, a certain coherence exists between the writing of space (represented by the abstraction of the urban grid) and the actual uses that take place there. One can assume to be in front of what is defined by the sociologists of space as "space of crossing". This last is an urban or territorial space that admits a single possible relational condition: that of constituting a vector of displacement from a point $\mathrm{A}$ to a point $\mathrm{B}$ of the space without allowing any belonging of the traveler to the place crossed if not mediated by any written information such as road signs, advertisements, illuminated signs [15].

\subsection{Correlation with land freight flows generated by SSS}

The Space Syntax Analysis does not allow to carry out impact analyses, with respect to the dynamics of the logistics flows that affect some roads connected to the port. Nevertheless, it is able to provide useful elements to carry out quantitative comparisons between different scenarios, involving modifications of the urban grid supposed a priori, in relation to the 
stresses deriving from external factors, such as, for example, the increase in heavy traffic on certain urban routes.

The modifications scenario, to be submitted to the Space Syntax Analysis, is determined by hypothesizing that the transformation of a specific urban area into a "crossing space" involves a specialization of the road segments which characterize it, until the arise of a pronounced monofunctionality with respect to all the possible types of traffic flows. To simulate such a scenario it is necessary to assume that the road axis concerned tends to progressively reduce its connectivity due to the interruption of the connections with the other transverse axes of the urban grid, maintaining only the longitudinal flowing function.

In the urban grid model, therefore, we must artificially interrupt the connections between the considered axial line and the other axial lines that are inserted orthogonally, thus producing an axial line connected only to its own ends, whose topological connectivity decreases and the average depth increases.

This has the effect of also significantly reducing the natural movement generated by the geometry of the urban grid on this axis, since it is more isolated than the rest of the grid.

In this last part of the study we therefore hypothesized that via La Farina performs the exclusive function of crossing for the heavy traffic flows generated by the SSS services of the port of Messina; in this hypothesis, the urban grid model has been modified by simulating the $90 \%$ reduction in transverse connections (scenario 2 corresponding to a full specialization of the road axis).

The urban grid modified in this way, has undergone the Axial Analysis, to verify the occurrence of alterations in the system of topological relations between the components of the grid.

\subsubsection{Analysis of scenario 2 (modified)}

In scenario 2 , the distribution of the local integration index with radius $=3$ shows a significant variation; it assumes values from a minimum of 0.2108 to a maximum of 4.0186 . The number of more integrated lines, that are contained in the field above the 80th percentile, are only 9, while they were 49 in scenario 1 (current). This means that in the modified scenario the
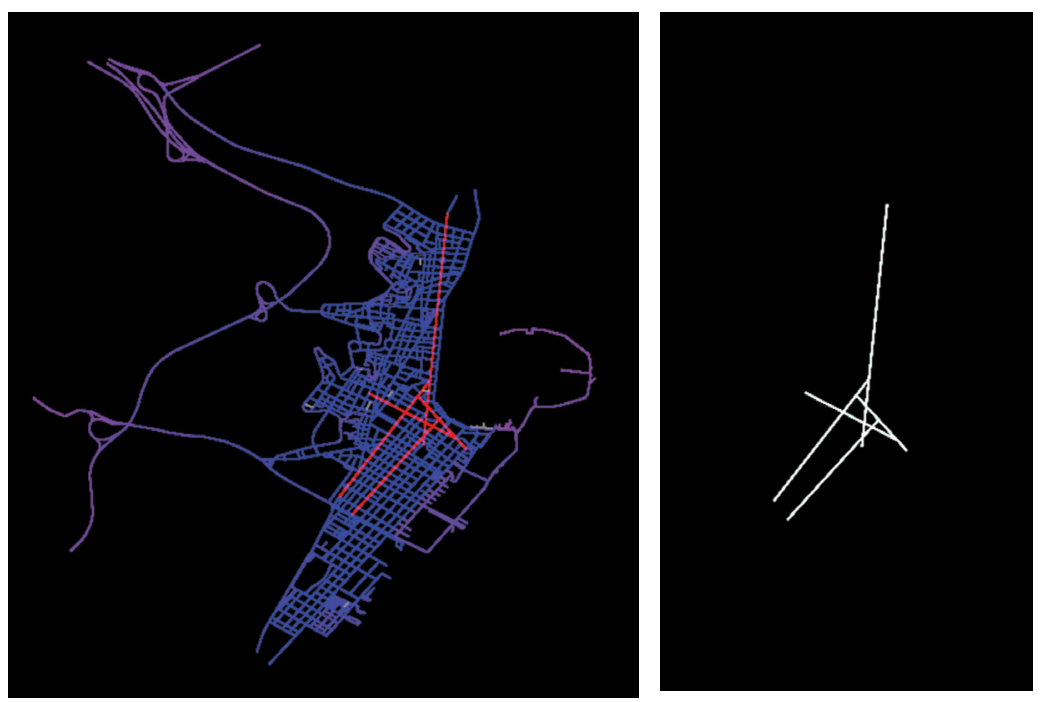

Figure 12: Global integration $R=n, 2019$. 
number of lines with higher integration values has decreased by approximately $81 \%$ compared to the current scenario.

Also the distribution of the global integration index of radius $=n$ (Fig. 12) shows different values; in fact in this case the number of more integrated lines that are contained in the field above the 80 th percentile are 5 , while they were 55 in scenario 1 (current), with a decrease of about $90 \%$.

The reduction of the values of the integration indices towards lower values leads to a redistribution of the weight of the axial line with respect to its own location; therefore, there is also a shift in the barycenter of the integration centre.

In Fig. 13, the barycenters of the integration cores corresponding to the radii $R=3, R=7$, $R=15$ and $R=n$ have been mapped. It can be noted that the transformation of Via La Farina into an urban crossing road axis involves the progressive shifting towards the south of each barycenter, however always falling in the most central urban sector, on the west of Via Garibaldi. The greatest displacement is undergone by the local integration center for $R=3$, moved southwards for about $500 \mathrm{~m}$. On the other hand, we note a not very significant shift of the global integration center, valued at just $70 \mathrm{~m}$.

In the specific of the single axial line corresponding to via La Farina, we also note that the values of the topological connectivity index are reduced from 20 to 4 due to the interruption of the transversal connections, while its average depth increases slightly from 14.43 to 14.97.

Finally, the described analysis does not seem to reveal a substantial alteration of the geometric distribution of the integration indices in the two scenarios taken into consideration, because for each more integrated axial line the decrease of these values between the two scenarios fluctuates between $9 \%$ and $10 \%$. Even the most integrated axial lines remain

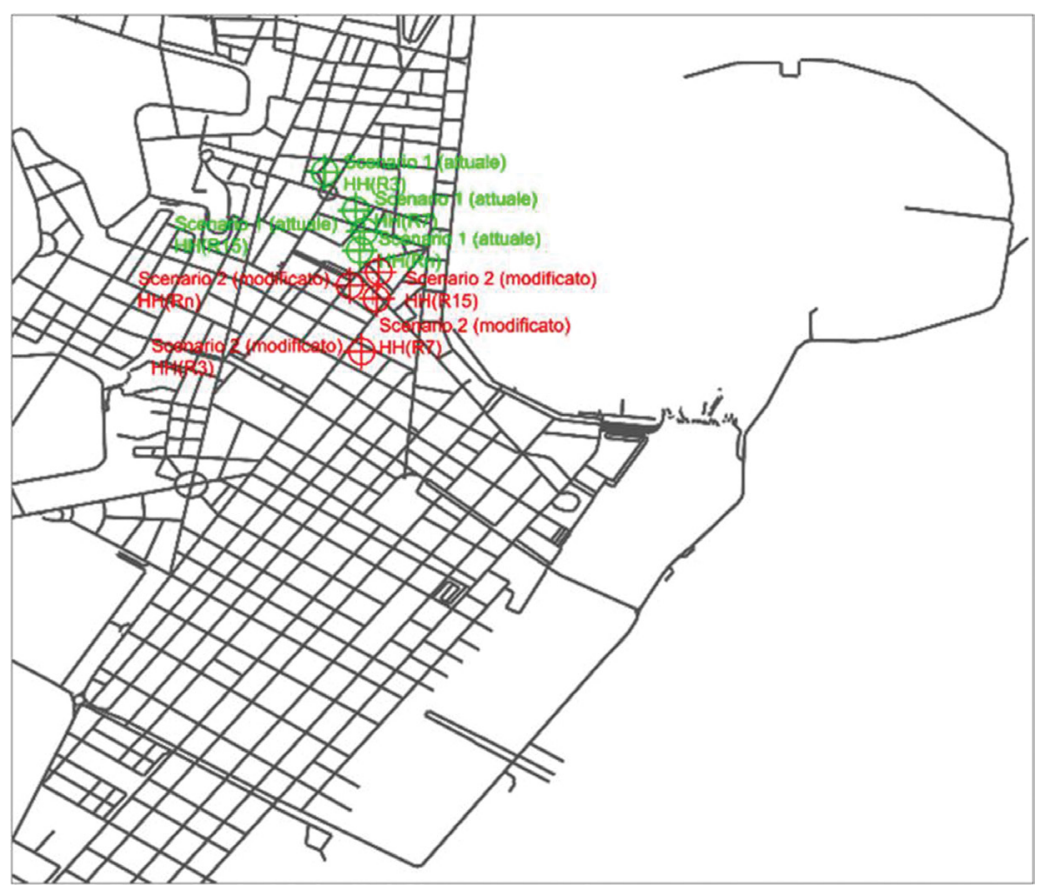

Figure 13: Barycenters of the integration cores, 2019. 
practically the same (compare Figs. 13 and 17 with Figs. 19 and 20), although with smaller index values. The axial line system constituting the Messina waterfront is not an exception, whose integration values are reduced, in scenario 2 , by approximately $9.3 \%$, thus loosing further natural movement quotas compared to the current scenario. This issue leads to the conclusion that the transformation of via La Farina into an urban crossing road axis for the direct connection of the port to the access/exit roads involves a certain alteration in the topology of the Messina urban grid, further reducing the natural movement quotas that interest the port waterfront, which, therefore, accentuates the specialist character of its road axes. However, this study confirms the permanence, in the two scenarios taken as a reference, of the same relational qualities in the urban grid, as they do not significantly change the axial lines that structure the integration nuclei.

\section{CONCLUSIONS}

The analysis carried out so far has enabled us to understand with a certain degree of objectivity, guaranteed by the mathematical tool used, the evolution over time of the connection relationship that the Messina waterfront has established with the rest of the urban pattern.

We have seen how this relationship has changed in relation to the expansion of the urban grid in the north-south direction, produced by the growth following the cataclysmic events that the city underwent in the years 1748 and 1908, and how the morphology of urban patterns created after such events has conditioned the relations between these and the port waterfront.

It was found that the 17th century city turned substantially towards its interior, because the structure of the urban grid did not favor the displacements towards the front of the port. This is probably due to an urban structure built when the port was still separated from the city by defensive walls, then replaced with a curtain of inhabited buildings, as shown by the cartographic representations of the time. The space of the 17th-century waterfront was therefore born outside the city and was subsequently connected to it with the demolition of the walls, when already the structure of the road network was consolidated.

It has also been highlighted that the urban design adopted by Messina during the whole 18th century, and characterized in its overall architectural image by the monumental system represented by the great neoclassical "Palazzata", by the Cittadella and the Forte di San Salvatore, also constituted an urban centrality, and as such, it was able to accommodate flows of natural displacements, not necessarily related to specific port functions. We can imagine the space of the portal waterfront as an urban square, place for walking and meeting, for itinerant trade and for carriages transit.

It was also highlighted how the new road layout created with the Borzì master plan, after the almost total destruction suffered by the city with the earthquake and tsunami of 1908, and the expansions to the south provided by the same master plan, have further moved the city center towards the Mosella districts and the Lombardo district, moving the city centre away from the front of the port. However, this has not led to a marginalization of the waterfront but rather to its further transformation as an urban sub-centrality, characterized by a significant specific coherence and by a strong connection to the roads of greatest preference for urban access and crossing displacements. This feature, combined with the fact that the waterfront appears to be endowed with a certain functional autonomy with respect to the central core of the city, has made it possible to identify the Messina waterfront as a "space of crossing".

This autonomy, however, does not exist for all the road layout involved in the displacement flows from the port to the junction with the A18, as they cross roads internal to the urban pattern, such as Via La Farina, whose actual structure does not seem to have the characteristics of an extra-urban road, due to the presence of trees at the center of the roadway, the narrowness 
of traffic lanes, the presence of parking along the road, the small size of the footpaths of the building blocks and, finally, the predominantly residential character of the buildings that compose them. Therefore the spatial system of the port waterfront, which by its current nature and function collects, among others, the freight transport flows of the Motorways of the Sea and of SSS, has its best (from the topological point of view) road connection of exit in the road trunk of Via La Farina, before entering in Viale Europa to reach the A18 motorway.

However, Via La Farina represents an improper connection for flows of vehicles and goods generated by the port and destined only to leave the city, because in this road are overlapped both the urban flows of internal and neighborhood trips and the port flows destined to outside the urban area, and among these a significant share is represented by the freight transport produced by the SSS. A possible specialization of Via La Farina towards freight transport to/from the Port, simulated in scenario 2, would imply a further strengthening of the port waterfront as a space for specialist use, as well as a shift towards the south of the local integration core, but this would not generate benefits to the trips which involve the urban edge overlooking the port.

\section{REFERENCES}

[1] Al Sayed, K., Space Syntax Methodology, Bartlett School of Architecture, UCL: London, 2018.

[2] Hillier B. \& Hanson J., The Social Logic of Space, Cambridge University Press: Cambridge, 1984.

[3] Hillier B., Hanson J., Grajewski J. \& Xu T., Natural movement: or configuration and attraction in urban pedestrian movement. Environment and Planning Part B, 20, pp. 29-66, 1993.

[4] Hillier B., Space is the Machine. A Configurational Theory of Architecture. Cambridge University Press: Cambridge, 1996

[5] Turner A., From axial to road-center lines; a new representation fo Space Syntax and new model of route choice for transport network analysis. Environment and Planning, Part B, 34 (3), pp. 539-555, 2007.

[6] Cutini V., La rivincita dello spazio urbano. L'approccio configurazionale allo studio e all'analisi dei centri abitati, Pisa University Press: Pisa, 2010.

[7] Cutini V., La forma del disordine. Tecniche di analisi e progetto urbano ai tempi dello sprawl, Mim Edizioni: Milano, 2016.

[8] Sabidussi G., The centrality index of a graph. Psichimetrika, 31(4), pp. 581-603, 1966.

[9] Borra S. \& Di Ciaccio A., Statistica. Metodologie per le scienze economiche e sociali, McGraw Hill Education: Milano, 2015.

[10] Sciascia L., Rapporto sulle coste siciliane, In Sciascia L. (ed.) La corda pazza. Scrittori e cose di Sicilia, Einaudi: Torino, pp. 204-213, 1970.

[11] Giuffrè M., L'isola e il mare: il porto di Messina e altri porti. In Simoncini G. (ed.), Sopra i porti di mare, Leo Olschki Editore: Firenze, pp. 210-223, 1997.

[12] AA.VV., Dizionario enciclopedico di Architettura e Urbanistica, IER: Roma, 1969.

[13] Ioli Gigante A., Messina. Storia della città tra processi urbani e materiali iconografici. Libreria Ciofalo: Messina, 2010.

[14] Tacconi G., Ricostruzione post sisma. Messina 1908, la città che visse due volte. Teknoring, 2016, available at https://www.teknoring.com/news/urbanistica/ricostruzione-post-sismamessina-1908-la-citta-che-visse-due-volte/ (acessed December 2019).

[15] Augé M., Non Luoghi. Introduzione ad una antropologia della surmodernità, Elèuthera, Paris, 1999. 